\title{
Prevalence and Determinants of Hypertension among African American Adults in Southwest Mississippi
}

\author{
Edith I. Ezekwe ${ }^{1}$, Azad R. Bhuiyan ${ }^{2}$
}

\author{
${ }^{1}$ Alcorn State University, 1000 ASU Drive \# 839, Lorman, Mississippi, 39096 \\ ${ }^{2}$ Jackson State University,350W.Woodrow Wilson Dr. Ste. 233, Jackson Medical Mall, Jackson Mississippi, \\ 39213
}

\begin{abstract}
Hypertension remains a devastating disease with high prevalence within African Americans (AA) communities in the state of Mississippi. The objective of the study was to determine the prevalence and determinants of hypertension among AA adults using secondary data from churches, soup kitchens, and health fairs in Vicksburg, Mississippi. The study was cross-sectional with a sample of 497 (67.8\% females, and 32.2\% males) AA adults. The data were analyzed using descriptive statistics to characterize the sample population. Chi-square test was used to determine the relationships between hypertension and age, gender, income, education, fruits and vegetable consumption (FVC), physical activity (PA), and health insurance. Adults with hypertension among this group were $35.2 \%, 39.0 \%$ had Pre-hypertension while $24.5 \%$ had normotensive rate. Significant $(\mathrm{P}<.05)$ associations existed between exercise, availability of personal doctors, and gender with hypertension while age, education, income, health insurance, FVC, and awareness of hypertension were not significant $(\mathrm{P}>.05)$. Only $11.0 \%$ of the participants consumed the recommended amount of daily fruits and vegetables, while 55\% did not exercise. This study showed that variables such as Exercise, Access to a Personal Doctor and Gender were all determinants for hypertension, also among this group, daily fruit/vegetable intake and physical activity were below recommended levels for adult population. Despite improved access to health insurance and increased awareness of hypertension, the prevalence of hypertension continues to be high in this community. Increased health screening, built environment, lifestyle modifications will positively impact hypertension, health disparities, and provide development of health policies to reduce prevalence of hypertension for adult Mississippians.
\end{abstract}

Keywords: Hypertension, African American, Risk Factors, Chronic, Mississippi

\section{Introduction}

More than $40 \%$ of African Americans or Blacks have high blood pressure or hypertension according to American Heart Association. Hypertension is called the silent killer because it rarely presents noticeable symptoms until serious problems have developed.

As a result of the delay in noticeable symptoms, there is a delay in treatment, hence, the great need for early screenings in places of convenience such as churches, health fairs, and soup kitchens. Hypertension is defined as a persistent and frequently progressive elevation in blood pressure. In the United States, African Americans develop hypertension at an earlier age than Whites. They also have a much higher average blood pressure reading, a higher likelihood of refractory hypertension, and higher rates of early hypertensive complications, including chronic kidney disease (CKD), stroke and heart disease. $(2,3,4)$
African Americans suffer from a three-fold higher death rate from hypertension with cardiovascular complications accounting for the majority of deaths (2). Data from the National Health and Nutrition Examination Survey (NHANES) indicated that although there has been a trend toward improving hypertension control among African Americans, the overall control remains low nationally. Prehypertension was common among young adults while older age group had more hypertension that has already progressed to clinical hypertension. Family history was not significant in determining the prevalence of pre- hypertension. Thus, indicating that an individual may develop prehypertension with or without a family history of hypertension, diabetes or cardiovascular diseases. The result showed that family history of diabetes was significantly associated with hypertension and higher BMI was associated with the prevalence of pre-hypertension and hypertension compared to patients with normal blood pressure. High prevalence of both overweight and obese subjects may, in turn, lead to a pre-hypertension and

This article is published under the terms of the Creative Commons Attribution License 4.0

Author(s) retain the copyright of this article. Publication rights with Alkhaer Publications.

Published at: http://www.ijsciences.com/pub/issue/2020-02/

DOI: 10.18483/ijSci.2264; Online ISSN: 2305-3925; Print ISSN: 2410-4477 
subsequently hypertension; leading to an increase in clinical complications and cardiovascular diseases (CVD). The Centers for Disease Control and Prevention (CDC) estimates that about 75 million United States adults (1 in 3 adults) have high blood pressure. Only about half $(54 \%)$ of these people have their high blood pressure under control (6). In the state of Mississippi more than 700,000 adults have hypertension, and thousands more may be at risk.

The hypertension prevalence rate from 2001- 2009 in Mississippi showed a wide disparity between Blacks (43.7\%) and Whites (34.7\%) (7). The hypertension rate for Mississippi was $42.4 \%$ in 2017, meaning 4 out of every ten adults in Mississippi have high blood pressure. Among African Americans, females had the highest prevalence of high blood pressure. A higher proportion of blacks reported high blood pressure than whites. Analysis of the socioeconomic determinants showed that adults with greater than high school education had a lower prevalence of high blood pressure compared to those with a high school education or less. The prevalence of high blood pressure increased as poverty increased. Those living within the Federal Poverty Levels (FPL) had a 66\% higher prevalence of high blood pressure than those living at $>300 \%$ FPL (8).

The Behavioral Risk Factor Surveillance System (BRFSS) reports that $35.6 \%$ of Warren County residents had high blood pressure in comparison to the state's percentage of $35.5 \%$. (9)

The secondary data used for this research study was obtained from Mississippi Delta Health Collaborative (MDHC). The overarching goal of Healthy People 2020 is to reduce by a target of $26.9 \%$ the proportion of adults with high blood pressure. The Healthy People 2020 goals are at the core of this study where 700,000 adult Mississippians, which translate to 4 out of 10 adults with hypertension and other co-morbidities, associated with chronic hypertension. Understanding and reducing socioeconomic and racial-ethnic disparities in health is arguably the most significant challenge facing U.S. public health research and policy. Despite abundant research on these social disparities in health, important questions remain regarding the reasons for the observed differences, which do not appear to be fully explained by the traditional individual-level risk factors included in most analyses. Reasons for social disparities in the individual-level risk factors themselves are also not well understood. (10)

\section{Objectives:}

This study was aimed to 1) Determine the prevalence of hypertension among AA adults using secondary data from churches, soup kitchens, and health fairs in Vicksburg, Mississippi.

2) Determine the predictor variables associated with hypertension based on the collected data in this community (including age, gender, income, education, fruits and vegetable consumption, physical activity, and health insurance).

\section{Methods}

The cross-sectional study design was used to measure the prevalence and determinants of hypertension using 497-convenient adult sample 18 years and older of AA who resided in Warren County of Southwest Mississippi. Sample size calculation used the formula by McKenzie

et al, 2005 (Samples: Churches 178 adults, Soup Kitchens 250 adults, Health Fair 69 adults). The confidence interval was set at $95 \%$; the margin of error was set at $5 \%$. This sample size is adequate for adjusting for much missing collected data. Secondary data from Delta Alliance for Congregational Health (DACH) was used for this study.

The study was conducted by all institutional and ethical guidelines in its procedures and conduct. Approval by the Jackson State University's Institutional Review and approval were obtained before starting the research study. Data Collection was conducted by trained interviewers who administered a structured questionnaire upon admission. The questionnaire was administered in a nonjudgmental manner to optimize participant's disclosure.

Each participant read and filled out a consent form to allow participation in the health screening. Blood pressure measurements were obtained in the left arm with seated position using standard mercury sphygmomanometer BP cuff. The second BP measurement was taken after five minutes of the first measurement. Finally, the average of the two readings was considered as the final $\mathrm{BP}$ of each participant. Hypertension was defined as systolic $\mathrm{BP} \geq 140 \mathrm{mmHg}$ or diastolic $\mathrm{BP} \geq 90 \mathrm{mmHg}$. The data collecting instrument was developed based on the operational dependent and independent variables for health screening purposes. The instrument included 32 short answer questions with close-ended -yes, no, and don't know answers. The questions included self-report scales designed to address constructs of the social cognitive theory, which included expectations for preventive health screenings, self-efficacy for participating in 
preventive screening, self-efficacy in overcoming barriers for participating in preventive health screenings, self- control, and environment. The original 32-item instrument was developed and validated for content validity, face validity, and readability by panel experts from Mississippi State Department of Health. The instrument was approved by the Mississippi Department of Health Institutional Review Board (IRB) - (MDH 101011). The questionnaire instrument was divided into three sections: Section 1. Covered items include demographic information such as age, education level, income, and gender. Section 2. Covered Health behavior for hypertension, diet and exercise, health insurance, and includes Yes, No or Don't Know answers. Section 3.

Covered Health screenings, included measurements for height, weight, and blood pressure.

\section{Statistical Analysis:}

Data analysis included descriptive statistics, Chisquare tests to compare demographic variables, and bivariate cross tabulations to define associations among different variables. The Statistical Package for Social Sciences (SPSS) version 21 was used to analyze data for the study. Alpha significance levels were set at 0.05 .

\section{Results:}

The sample population is mostly African Americans. Education was categorized as high school/GED, vocational school, and college/university. Hypertension awareness prevalence was stated in a question format - Has your doctor told you that you have hypertension? The answer was categorized as Yes, or No. Measured blood pressure was categorized as normal $(<120 /<80), \quad 120 / 80-139 / 89$ or high $(>140 />90)$.

The age of the sample population was categorized into two groups ( $<55$ and $>55$ years). Gender was identified as male or female.

Percentage of adults with high school education was $57.7 \%$, Vocational school was $10.3 \%$, and college/university education was $32.0 \%$. The cross tabulation of Hypertension Frequency and Percent of Normal, At-risk, and Hypertension Based on the Education of the Sample Population showed the largest group of participants with a high school education had the highest hypertension rate of $35.3 \%$, an at-risk rate of $39.9 \%$ and $24.7 \%$ with a normotensive rate. Participants with college/university education in this sample population had hypertension rates of $33.1 \%$, an atrisk hypertension rate of $30.8 \%$ and a normotensive rate of $32.2 \%$ the differences were not statistically significant $(\mathrm{P}>0.05)$. Those making less than $\$ 50,000$ had a $37.7 \%$ hypertension rate, $37.0 \%$ had the at-risk hypertension rate, and $25.3 \%$ had normotensive rate. Those making more than $\$ 50,000$ had a $32.2 \%$ hypertension rate, $44.3 \%$ had the at-risk hypertension rate, and $24.6 \%$ were in the normotensive rate. Of noteworthy was that $80.5 \%$ of the participants had health insurance. Among those with health insurance $35.2 \%$ had hypertension, $40.8 \%$ had at-risk hypertension rate, and $24.1 \%$ were normotensive. Among those that do not have health insurance, $37.5 \%$ had hypertension, $35.4 \%$ had at risk hypertension, and $27.1 \%$ were normotensive.

The results of crosstabs analysis to examine the participant's fruit and vegetable consumption on hypertension (Normal, At-risk, and Hypertension) showed that the rate of hypertension was $35.8 \%$, atrisk hypertension rate was $40.0 \%$, and $24.2 \%$ for the normotensive group (Table 2). In the group that ate fruits and vegetable 1-4 times per day, hypertension rate was $34.5 \%, 37.9 \%$ for the at-risk group, and $27.6 \%$ for the normotensive group. The relationship between hypertension of the participants and fruits and vegetable consumptions were not significant $(\mathrm{p}>0.05)$.

The cross-tabulation of physical activity and hypertension revealed an inverse relationship between physical activity and hypertension (Table 3 ). Adults that did not engage in physical activity had a high rate of hypertension at $68.3 \%$ while those that engaged in physical activity had lower hypertension rate of $49.6 \%$. $(\mathrm{P}<0.001)$ When the question "Do you have a personal doctor?" was asked, those without medical doctor had $45.4 \%$ hypertension rate while those that have a personal doctor, had 63.5\% ( $\mathrm{P}<0.001)$ hypertension rate.

\section{Discussion and Conclusion}

Within this community-based sample of African American adults, there were several important findings revealed by the study (Table 1). On the demographic variables the significant findings were: More than half of the participants had high school education. The data showed that lower educational levels were associated with higher hypertension rates $(\mathrm{P}>0.05)$. Almost twothirds of the participants made less than $\$ 50,000$ and had higher rate of hypertension $(\mathrm{P}>0.05)$. There were high prevalence of prehypertension and hypertension at $74.2 \%$. Two thirds of the participants were females while one third were males. Within this group, the males had a higher rate of hypertension than women. $(\mathrm{P}>0.05)$ More participants were employed compared to unemployed. The percentage of >55year old was a little more and had higher 
hypertension rate than the <55year old.

On the frequencies and percentages of personal responses to questions on the questionnaires, more adults were aware of having hypertension compared to those that were not aware of having hypertension.

Awareness prompted them to seek more medical intervention. Three-quarters of the participants had access to personal doctor compared to one quarter without a personal doctor. Though the majority of the participants had personal doctor, this group also had higher hypertension rates, suggesting that this is due to patient noncompliance.

Three-quarters of the participants had access to health insurance compared to one quarter without health insurance. Almost ninety percent of the adult population did not eat the USDA recommended daily amount of fruits and vegetables. According to the $\mathrm{CDC}$, Behavioral Risk Factor Surveillance System (9) data, the hypertension rate was highest among people with less education. Those with less than a high school graduation reported a $43.7 \%$ hypertension rate. High school grads reported a $40.9 \%$ hypertension rate. College grads had the lowest hypertension rate at $27.8 \%$.

These findings were in agreement with the present study, but in contrast with those of (11) that showed a significant association between education and the prevalence of hypertension. Further, respondents with graduate education relative to those without High School were 28\% less likely to be diagnosed with hypertension. This is in agreement with those of others $(9,12,13,14,15,16)$. When the result was crosstabulated among normotensive and hypertensive groups based on education, the results were not significant $(\mathrm{P}>0.05)$.

The lack of significance might be due to the variations in data, missing data, and the uniqueness of the population studied. Education has a positive effect on adherence to lifestyle modifications, medication recommendations, adherence to clinical care. It also elicits understanding of the burden of hypertension which translates into the prevention of cardiovascular complications such as hypertension (18).

\section{Income:}

Our data showed an inverse relationship between income and hypertension. These results showed trends seen in other studies where income has an inverse relationship with hypertension. People with lower income had a higher prevalence of hypertension than those with higher income. This observation is supported by trends seen in other studies that reported hypertension decreased with increasing income levels (14, 19, 20, 21, 17,).

Centers for Disease Control and Prevention Behavioral Risk Factor Surveillance System data from (22), showed the highest hypertension rate for adults with a lower income of $<\$ 25,000$ at $42.8 \%$ compared with adults making \$50,000$\$ 74,000$ with hypertension rate of $33.4 \%$. Contrary to our observation, results of a study by Opara (11) which compared the prevalence of hypertension among Hispanics, Caucasians and African Americans, showed that Caucasians who had higher income had higher hypertension prevalence compared to Hispanics, but not to African Americans. The relationship between hypertension and income was not statistically significant $(\mathrm{P}>0.05)$ this may be due to missing data $(57 \%)$, variations in collected data and uniqueness of the population.

People do not like to answer questions on income since it represents an invasion of privacy. For future studies, the researcher collecting the socioeconomic information should make greater effort in reassuring the participants that all their information will be treated with utmost integrity.

Health Insurance: Participant's response to the question -Do you have any health insurance? ॥ showed that majority of the sample population $(8$ in 10) of participants had health insurance (Table1) This result is consistent with previous results that showed $89.2 \%$ of study participants had insurance coverage while $10.8 \%$ did not have health insurance coverage $(23,11)$ According to CDC 2012 data on Awareness and Treatment of Uncontrolled Hypertension among the

Adults- United States, 2003-2010, 85.2\% of the adults had health insurance. Though there has been an increase in health insurance coverage for adults 18-64 due to the Affordable Care Act mandates (Obama Care), prior studies from the Urban Institute's Health Reform Monitoring System showed during the first half of 2014, the disparities in access to care remained

In our study, cross-tabulation of hypertension (Normal, At-risk, and Hypertension) with access to health insurance revealed that those with health insurance had a lower prevalence of hypertension compared to those without health insurance. Similar results were seen by Djoukeng, (13) study. This is in contrast to those of $(14,24,25)$, whose study results showed a higher prevalence of hypertension among those with health insurance compared to those without health insurance. The relationship between hypertension (Normal, At-risk, and 
Hypertension) and health insurance was not significant. (P>0.05) The cross-tabulation of hypertension (Normal and Hypertension) and health insurance showed no significant relationships $(\mathrm{P}>0.05)$ between the groups.

\section{Fruit and Vegetable Consumption:}

The question "How many times do you eat fruits and vegetables per day?" indicated low consumption of fruits and vegetables among this sample population. The trend is similar with results of other studies across the state and nation

$(26,22$,$) which showed a high percentage of adults$ eating less than recommended daily 5 servings of fruits and vegetables per day. The previous study in Mississippi on consumption of fruits and vegetables also showed lower daily consumption of fruits and vegetables than recommended according to 2010 dietary guidelines (22). An interesting finding was that among those who ate 1-4 times of fruits and vegetables, the prevalence of hypertension was very high compared to those that ate more than five servings of daily fruits and vegetables. This study indicates a substantial gap between the recommended and the actual level of fruit and vegetable intake in this sample population which negatively impacts hypertension severity. Though the trend was similar to other findings, the result was not statistically significant $(\mathrm{P}>0.05)(28)$

The crosstabs analysis to examine the participants' fruits and vegetable consumption on hypertension based on Normal and Hypertension groups showed similar trends

The relationship between hypertension (Normal and Hypertension) of the participants and fruits and vegetable consumption were not significant $(\mathrm{P}>$ 0.05). Benefits of eating fruits and vegetables include lower hypertension rate, lower cancer, coronary heart, stroke, and other chronic diseases. Lack of fruit and vegetable consumption have been attributed to a myriad of reasons such as; cultural rooted food preferences, environmental barriers such as access to fruit and vegetable in disadvantaged neighborhoods, costs, lack of knowledge of translating dietary guidelines into daily meals consumption. To increase daily consumption of fruits and vegetables, concerted efforts must include outreach programs at individual, family, community, and school levels, to address lifestyle behavior and environmental barriers to eating fruits and vegetables. (28)

\section{Exercise:}

The cross-tabulation of physical activity and hypertension revealed an inverse relationship between physical activity and hypertension (Table 5). Adults who did not engage in physical activity had a higher rate of hypertension while those that engaged in physical activity had lower hypertension rates. The relationship between exercise and cross-tabulation of hypertension (normal and hypertension) and physical activity was highly significant $(\mathrm{P}<0.001)$. This agrees with other numerous findings that reported that a positive association between low hypertension and exercise $(29,30)$ Also, the previous study in Warren County documented the low prevalence of recommended physical activity in 2011 with $40.1 \%$ of females and $47 \%$ of males getting recommended physical activity. The National average in 2011 was $52.6 \%$ for females and $56.3 \%$ for males (31).

When results of physical activity and hypertension were stratified according to gender among Mississippi adults, black females exercised at a higher rate than the males Reports from the Burden of Chronic Diseases in Mississippi, 2014 also, showed that $70 \%$ of African Americans do not engage in physical activities due to various environmental barriers $(32,29)$.

A study by Opara (11), showed that in all racial/ethnic groups, exercise was below average, with the Hispanics having the lowest prevalence of exercise, $20.1 \%$, versus Caucasian $(28.8 \%$ ) and African Americans (24.6\%). Our findings of physical activity and hypertension were highly significant $(\mathrm{P}<0.05)$. About one in every three U.S. adults (31 percent) reports participating in no leisure-time physical activity. American Heart Association recommends 60 minutes of exercise every day. Only $18.0 \%$ of non-Hispanic blacks age 18 and older met the 2008 Federal Physical Activity Guidelines. Barriers to physical activity include; a planned and structured environment including; sidewalks, safe adequately lit neighborhoods, bicycle paths, public recreation centers, community gardens, and proper control of stray animals.

Additionally, some work conditions may allow no leisure time and health problems may be prohibitive to exercise for some.

\section{Access to Personal Doctor:}

The results of the question: "Do you have a personal doctor?" cross- tabulated with normal At-risk and hypertension revealed that more adults with access to the personal doctor had higher hypertension rates than those that did not have access to a personal doctor. Our results were higher than those of Fang from Behavioral Risk Factor Surveillance System (9). In their study, the prevalence of those 
without a personal doctor was $9.2 \%$ in Massachusetts and $32.7 \%$ in Nevada and the prevalence of cost barrier to visiting a doctor ranged from $10.8 \%$ in North Dakota to $35.1 \%$ in Tennessee. The age-standardized prevalence of those without a personal doctor or health care provider was $23.6 \%$ for those with hypertension. High prevalence of hypertension with adults who reported having access to a personal doctor, could be due to the cost associated with medical visits, lack of affordability of medication, and lack of transportation to office visits.

The relationship between hypertension and exercise and having personal doctor were highly significant. $(\mathrm{P}<0.05)$

The cross-tabulation of hypertension (Normal and Hypertension) and access to the personal doctor revealed similar results and were highly significant.

\section{Awareness of Hypertension:}

The cross-tabulation of hypertension awareness posed in the form of question "Has a doctor ever told you that you have blood pressure?" revealed more adults were aware of having hypertension. This is in agreement with previous studies $(33,34$, 35, 36,37). Age is one of the reasons for the increased hypertension awareness. As people age, they are more interested in longevity and their health status than the younger generation. Older adults tend to be more aware of their hypertensive status, while young adults tend to have unusually low hypertension awareness. Because younger individuals tend to be healthier, they are less likely to see doctors on a regular basis, decreasing the likelihood that they will have accurate and up-todate knowledge of their blood pressure status. Interesting findings revealed that the prevalence of hypertension and pre-hypertension were higher among those not aware of hypertension. The findings suggested that for the populations unaware of their hypertension, regular medical visits, more health screenings, and more outreach programs are critically necessary for decreasing hypertension and prehypertension prevalence. Other research studies have shown that men have higher levels of hypertension and lower levels of hypertension awareness than women. There is a paucity of information on these differences that emerge among young adults. The National Longitudinal Study of Adolescent to Adult Health, (36) found that among the groups with hypertension, Blacks living in the disadvantaged neighborhood were more likely than Whites to be aware of their condition. (12) The relationship between hypertension (Normal, At- risk, and hypertension) and hypertension awareness was not significant $(\mathrm{P}>0.05)$. Cross- tabulations of hypertension (Normal and Hypertension) and awareness of hypertension was not significant $(\mathrm{P}>0.05)$
Addressing the Social Cognitive Theory in the context of this study

Social Cognitive Theory (SCT), (Bandura, 1986) explains human behavior as a three- way, dynamic, reciprocal model which postulates frequent interaction between personal factors, environmental influences, and behavioral capability. The central idea of SCT is that people learn through their own experiences, through observation of the actions of others and the results of those actions. Using SCT as Theoretical Framework, these questions were tested: In this study, only $12 \%$ of the participants reported consuming the recommended daily amount of fruits and vegetable while, $88.6 \%$ did not. However, the relationship between the daily servings of fruits and vegetables and systolic and diastolic blood pressure was not significant $(\mathrm{P}>0.05)$.

Study Limitations: The study though with significant findings had some limitations. This sample population may not be an accurate representation of the general population nor can the findings be extrapolated to state and national data. The sample population was mostly African Americans which can introduce cultural bias. The response rate for some of the questions on the questionnaire was not adequate such as in answering the question on income, hence a lot of missing values.

\section{Strengths of this study:}

The study participants were all African Americans which helped to understand the critical contributing factors, priorities for this at-risk population, lifestyle dietary behavior, and environmental modification to be made in hypertension intervention studies as results of this study. There is a critical need for public health professionals to address the determinants that drive hypertension, and environmental changes, in this sample of African American adult population in southwest Mississippi. The significant finding of this study will help in designing a long-term hypertension prevention research in this vulnerable population.

\section{Conclusion:}

Significant findings of this study are; exercise, access to a personal doctor, and gender had an association with hypertension and are strong determinants for hypertension. The daily consumption of fruits and vegetables were substantially below the recommended amount. The participants' daily physical activity was below recommended levels for adults.

Even though more people have access to health insurance and are aware that they have 
hypertension, the prevalence of prehypertension and hypertension continues to be high in this community. The results showed urgent needs for healthy lifestyle, continued health outreach program, user-friendly built environment, and health screenings in this community of Vicksburg Warren County Mississippi. The findings from this study will contribute to designing intervention strategies and prevention measures for hypertension. The impact will be a reduction in hypertension health disparities, and positively provide development of health policies for adult Mississippians.

\section{Recommendations for Future Research:}

Based on the key findings of this study, the prevalence of pre-hypertension and hypertension in this community was still high $(39.0 \%$ and $35.2 \%$ respectively). These results call for effective strategies to reduce hypertension in this community. One in six adults who did not engage in physical activity had hypertension.

Outreach programs should include current recommendations on preventive steps centered on non- pharmacological interventions. These interventions include lifestyle modifications such as weight reduction, increased physical activity, and reduced dietary salt intake, increase of daily fruit and vegetable consumption and smoking cessation. The preventive steps should involve the community more, especially for young adult health screenings based on current recommendations.

Educators and healthcare professionals are encouraged to articulate the systemic physical, mental, and economic burden of hypertension on individuals and families through various channels such as the media, community organized health fairs and churches.

Environmental infrastructure such as sidewalks, bicycle paths, safe well-lit neighborhoods, proper control of stray animals, and community gardening are recommended as measures to reduce hypertension.

The cross-tabulation of physical activity and hypertension revealed an inverse relationship between physical activity and hypertension (Table 2 ). Adults that did not engage in physical activity had a high rate of hypertension at $68.3 \%$ while those that engaged in physical activity had lower hypertension rate of $49.6 \%$. When the question "Do you have a personal doctor?" was asked, those without medical doctor had $45.4 \%$ hypertension rate while those that have a personal doctor, had $63.5 \%$ hypertension rate.

\section{Acknowledgements}

Sincere gratitude goes to Dr. Michael Ezekwe, Dr. Frank Mrema, Ms. Cinda Catchings, from Alcorn State University, School of Agriculture and Applied Science, and Ms. Laura Turner from Jackson State University School of Public Health for editing the manuscript, to Ms. Vanessa Prentice from Triumph church, Vicksburg, MS who made available the raw data for the research.

\section{Authors' contributions}

EIE conceived the study and conducted the statistical analysis with help from Dr. Clifton Addison, Jackson Heart Study, Jackson, MS. All authors contributed to the interpretation of results, revision and approval of original study manuscripts.

\section{Competing interests}

The authors declare that there is no conflict of interest regarding the publication of this manuscript.

\section{Ethics approval and consent to participate}

Consent and approvals were sought from IRB, (Jackson State University IRB: \# 0194-16) and sample participants.

Table 1: Demographic Characteristics of African American in Warren County, Mississippi

\begin{tabular}{|c|c|c|}
\hline Items & Frequency & Percent \\
\hline \multicolumn{3}{|l|}{ Race/Ethnicity } \\
\hline Black, non-Hispanic & 497 & 100 \\
\hline \multicolumn{3}{|l|}{ Gender } \\
\hline Male & 160 & 32.2 \\
\hline \multicolumn{3}{|l|}{ Age (yrs.) } \\
\hline$<55$ years & 248 & 49.9 \\
\hline$>55$ years & 249 & 50.1 \\
\hline
\end{tabular}


Prevalence and Determinants of Hypertension among African American Adults in Southwest Mississippi

\begin{tabular}{lll} 
Total & 497 & 100. \\
Income & & \\
$<\$ 50,000$ & 313 & 63.0 \\
$>\$ 50,000$ & 184 & 37.0 \\
Total & 497 & 100. \\
Education & & \\
High school diploma & 287 & 57.7 \\
Vocational school & 51 & 10.3 \\
College degree & 159 & 32.0 \\
Total & 497 & 100.0 \\
Employment & & \\
Not employed & 186 & 37.5 \\
Retired & 99 & 19.8 \\
Employed & 199 & 40.1 \\
Missing values & 13 & 2.6 \\
Total & 497 & 100. \\
\hline
\end{tabular}

Table1. (Continued) Frequency and Percentage of Personal Response to Questionnaire among African American in Warren County, Mississippi

\begin{tabular}{lcc}
\hline Item & Frequency & Percent \\
\hline Has a doctor ever told you that you have high blood pressure? (Awareness) & \\
\hline No & 229 & 46.1 \\
Yes & 268 & 53.9 \\
Total & 497 & 100. \\
\hline Do you have a personal doctor? & & \\
No & 92 & 18.5 \\
Yes & 405 & 81.5 \\
Total & 497 & 100 \\
\hline Do you have health insurance? & & \\
No & 97 & 19.5 \\
Yes & 400 & 80.5 \\
Total & 497 & 100. \\
\hline Do you Exercise? & \\
\hline No & 271 & 54.9 \\
Yes & 223 & 45.1 \\
Total & 494 & 100. \\
\hline How many times do you eat fruits and vegetables per day? & \\
\hline 1-4 times & 436 & 88.3 \\
5 or more times & 58 & 11.7 \\
Total & 494 & 100. \\
\hline
\end{tabular}

Table2. Prevalence of Hypertension of the Sample Population

\begin{tabular}{lll}
\hline Item & Frequency & Percent \\
\hline Normal (<120/80) & 122 & 24.5 \\
At Risk (120/80-139/89) & 194 & 39.0 \\
High (> 140/90) & 175 & 35.2 \\
Total & 491 & 98.8 \\
Total & 497 & 100 \\
\hline
\end{tabular}


Table3. Cross tabulation between Hypertension status (Normal and High) and Personal Response to Exercise and Personal Doctor Questionnaires.

\begin{tabular}{|c|c|c|c|c|}
\hline Item & *Normal & $* * *$ High & Total & P-value \\
\hline \multicolumn{5}{|c|}{ Do you Exercise? } \\
\hline No & $51(31.7 \%)$ & $110(68.3 \%)$ & 161 & .001 \\
\hline Total & $151(39.9 \%)$ & $173(60.1 \%)$ & 288 & \\
\hline \multicolumn{5}{|c|}{ Do you have a personal doctor? } \\
\hline Yes & $85(36.5 \%)$ & $148(63.5 \%)$ & 233 & \\
\hline Total & $115(39.9 \%)$ & $173(60.1 \%)$ & 288 & \\
\hline
\end{tabular}

*Normal (<120/80 mm Hg)

***High (> 140/90 mm Hg)

The relationships between hypertension (normal and hypertension) with having personal doctor, and engaging in physical activity were highly significant $(\mathrm{p}<0.05)$

Table 4. Table 4 represents Crosstabs analysis to examine the participants' hypertension rate. (Normal, At-risk, and Hypertensive) based on age showed that among the < 55-year-olds, $29.3 \%$ were normotensive, and $36.6 \%$ had at risk hypertension while $34.1 \%$ were hypertensive. Among the $>55$ year-olds, $20 \%$ were normotensive, $42.9 \%$ were at risk, while $37.1 \%$ were hypertensive. The relationship between age and hypertension was not significant (p. >05)

Table 4. Cross Tabulation of Hypertension Frequency and Percent (Normal, At-risk, and Hypertension) based on Age and of the Sample Population.

Percentage of $<55$ years old is $49.4 \%$ and $50.1 \%$ for $>55$ year old (Table 1 )

\begin{tabular}{lccccc}
\hline Item & $*$ Normal & $* *$ At Risk & $* * *$ High & Total & P-value \\
\hline Age & & & & & \\
\hline$<55$ & $72(29.3 \%)$ & $90(36.6 \%)$ & $84(34.1 \%)$ & 246 & \\
$>55$ & $49(20.0 \%)$ & $105(42.9 \%)$ & $91(37.1 \%)$ & 245 & \\
Total & $121(24.6)$ & $195(39.7 \%)$ & $175(35.6 \%)$ & 491 & \\
\hline
\end{tabular}

*Normal $(<120 / 80 \mathrm{~mm} \mathrm{Hg})$

**At Risk (120/80-139/89 mm Hg)

***High (> 140/90 mm Hg)

The relationships between hypertension rates, and age among the groups measured were not significant $(\mathrm{p}>.05)$

\section{References}

1. American Heart Association, https://www.heart.org/en/health-topics/high-bloodpressure/why-high-blood-pressure-is-a-silent-killer/highblood-pressure-and-africanamericanshttps://doi.org/10.1037/e419002008-001.

2. Mozaffarian, D., Benjamin, E. J., Go, A. S., Arnett, D. K., Blaha, M. J., Cushman, M., ... Turner, M. B. (2015). Heart disease and stroke statistics-2015 update: A report from the American Heart Association. Circulation, 131(4), e29e39. https://doi.org/10.1161/CIR.0000000000000152

3. Bibbins-Domingo, K, Pletcher, MJ, Lin, F, et al. Racial differences in incident heart failure among young adults. $\mathrm{N}$ Engl J Med. 2009;360(12):1179-1190. doi:10.1056/NEJMoa0807265

4. Calhoun D.A., Booth, J.N., Opara, S., Irvin, M.R. Shimbo, D., Lackland, D.T., Howard, G., Safford, M.M., \& Muntner, P. Refractory hypertension: determination of prevalence, risk factors, and comorbidities in a large, population-based cohort. Hypertension. 2014; 63:451-458.

5. Merai, R., Siegel, C., Rakotz, M., Basch, P., Wright, J., Wong, B., \& Thorpe P. (2016, November 18). CDC grand rounds: A public health approach to detect and control hypertension. MMWR Morbidity \& Mortality Weekly Report, 65(45)1261-1264.

6. https://doi.org/10.15585/mmwr.mm6545a3
7. Mendy, V. L., \& Vargas, R. (2015). Trends in major risk factors for cardiovascular disease among adults in the Mississippi Delta Region, Mississippi Behavioral Risk Factor Surveillance System, 2001-2010. Preventing Chronic Disease, 12, E21. Retrieved from https://www.cdc.gov/pcd/issues/2015/14_0481.htm.

8. Short, V. (2014, September). Report on the Burden of Chronic Diseases in Mississippi in 2014.Burden of Chronic Diseases in Mississippi, p. 22 \& 23.

9. Retrieved http://msdh ms.gov/msdhsite/ static/resources/4775

10. Behavioral Risk Factor Surveillance System (BRFSS) New York State 2011. Retrieved from https://health.data.ny.gov/Health/Behavioral-Risk-Factor-

11. Surveillance-Survey-2011.updated March 10, 2015

12 . Opara, F. I. (2010). Racial /ethnic disparities in hypertension in United States residents: A crosssectional study of potential explanatory covariates (Order No. 3397131).

13. Available from ProQuest Dissertations \& Theses A\&I. (193245113).

14. Morenoff, J. D., House, J. S., Hansen, B. B., Williams, D. R., Kaplan, G. A., \& Hunte, H. E. (2007). Understanding social disparities in hypertension prevalence, awareness, treatment, and control: The role of neighborhood context. Social Science Medicine. 
https://doi.org/10.1016/j.socscimed.2007.05.038

15. Djoukeng, J. T. (2016). Comparison of risk factors for hypertension among blacks, whites and Mexican Americans.

16. Retrieved

from:https://search.proquest.com/docview/1892091210?ac countid $=40672$

17. Guo J, et al., (2015), The dynamics of hypertension prevalence, awareness, treatment, control and associated factors in Chinese adults. J Hypertens. 2015 Aug;33(8):1688-96. 10.1097/HJH.0000000000000594.

18. Ghazali, S. M., Seman, Z., Kee Chee, C., Lim Kuang, H., Manickam, M., Lim Kuang, K.,\& Mustafa, A. N. (2015). Sociodemographic factors associated with multiple cardiovascular risk factors among Malaysian adults. BMC Public Health, 15(1), 1105- 1123.

19. https://doi.org/10.1186/s12889-015-1432-z

20. Kavanagh A, Bentley R.J., Turrell, G., Shaw, J., Dunstan, D., \& Subramanian S.V. (2010). Socioeconomic position, gender, health behaviors and biomarkers of cardiovascular disease and diabetes. Social Science Medicine, 71(6), $1150-60$

21. Smith, J., Lensing, S., Horton, J., Lovejoy, J., Zaghloul, S., Forrester, I., ... \& Bogle, M.L. (1999). Prevalence of self-reported nutrition-related health problems in the lower Mississippi Delta. American Journal of Public Health, 89(9), 1418-1421.

22. Beune, E. J., Moll van Charante, E. P., Beem, L., Mohrs, J., Agyemang, C. O., Ogedegbe, G., \& Haafkens, J. A. (2014). Culturally Adapted Hypertension Education (CAHE) to improve blood pressure control and treatment adherence in patients of African origin with uncontrolled hypertension: Cluster-randomized trial. PLoS ONE, 9 (3), $1-11$.

23. Williams, M.V., Baker, D.W., Parker, R.M., \& Nurss, J.R. (1998). Relationship of functional health literacy to patients' knowledge of their chronic disease. A study of patients with hypertension and diabetes. Archives of Internal Medicine 158, 166- 172.

24. MacLaughlin, E.J., Raehl, C.L., Treadway, A.K., Sterling, T.L., Zoller, D.P., \& Bond, C.A. (2005). Assessing medication adherence in the elderly: Which tools to use in clinical practice? Drugs \& Aging, 22: 231-255.

25. Fiscella, K., Winters, P., Tancredi, D., \& Franks, P. (2011). Racial disparity in blood pressure: Is vitamin D a factor? JGIM: Journal of General Internal Medicine, 26(10), 1105-1111. doi:10.1007/s11606-011-1707-8.

26. Centers for Disease Control and Prevention. (2017). State indicator report on fruits and vegetables. Retrieved from U.S. Centers for Disease Control and Prevention:

https://www.cdc.gov/nutrition/downloads/State-IndicatorReport-Fruits-Vegetables- 2013.pdf.

27. Mendy, V. L., Vargas, R., El-sadek, L., \& Short, V. L. (2016). Decreasing prevalence of no known major risk factors for cardiovascular disease among Mississippi adults, Mississippi Behavioral Risk Factor Surveillance System, 2001 and 2009. BMC Public Health, 16(1), 1-6.

28. Angell, S.Y., Renu, K., Gwynn, Bash, L., Thorpe \& Frieden, T. (2008). Prevalence, awareness, treatment and predictors of control of hypertension in New York City. Circulation: Cardiovascular Quality and Outcomes, 1(1):46-53

29. Keenan N.L., \& Rosendorf, K.A., (2011). Prevalence of
Hypertension and Controlled Hypertension United States, 2005-2008, National Center for Chronic Disease Prevention and Health Promotion, CDC Supplements January 14, 60(01); 94-97.

30. Dehghan, M., Akhtar-Danesh, N., \& Merchant, A. T. (2011). Factors associated with fruit and vegetable consumption among adults. J Hum Nutr Diet. 2011 Apr;24(2):128-34. doi: 10.1111/j.1365277X.2010.01142.x. Epub 2011 Feb 21.

31. Maimela, E., Van Geertruyden, J., Alberts, M., Modjadji, S. P., Meulemans, H., Fraeyman, J., \& Bastiaens, H. (2015). The perceptions and perspectives of patients and health care providers on chronic diseases management in rural South Africa: a qualitative study. BMC Health Services Research, 15(1), 1-12. doi:10.1186/s12913-0150812-5

32. Casagrande, S.S., \& Gary-Webb, T.L. (2010) Trends in US adult fruit and vegetable consumption. In R. Watson \& V. Preedy (Eds.), Bioactive foods in promoting health: Fruits and vegetables (111-130). Cambridge, MA: Elsevier.

33. Diaz J.J., \& Whitaker, R.C. (2013). Black mothers' perceptions about urban neighborhood safety and outdoor play for their preadolescent daughters. Journal of Health Care Poor \& Underserved 24 (1) 206-219.

34. Whelton, P.K., He, J., Appel, L.J., Cutler, J.A., Havas S, Kotchen, T.A., et al. (2002). Primary prevention of hypertension: Clinical and public health advisory from the National High Blood Pressure Education Program. JAMA, 288,1882-8.

35. Olives, C., Myerson, R., Mokdad, A.H., Murray, C.J.L., \& Lim, S.S. (2013) Prevalence, awareness, treatment, and control of hypertension in United States Counties, 20012009. PLOS ONE 8(4), e60308. https://doi.org/10.1371/journal.pone.0060308.

36. Armah IV, N. and Henderson, B.R. 2010. "Making the Case for Community-Based Wellness Programs." National Civic Review, 99 (1). 27-34. doi:10.1002/ncr.20006.

37. Chobanian A.V. (2010). Improved hypertension control: Cause for some celebration.Journal of the American Medical Association, 303(20), 2082-2083. https://doi.org/10.1001/jama.2010.692

38. Chobanian A.V. (2010). Improved hypertension control: Cause for some celebration.Journal of the American Medical Association, 303(20), 2082-2083. https://doi.org/10.1001/jama.2010.692

39. Ostchega Y., Yoon, S.S., Hughes, J., \& Louis, T. (2008). Hypertension awareness, treatment, and controlcontinued disparities in adults: United States, 2005-2006. NCHS Data Brief, 3. https://doi.org/10.1037/e403872008001

40. CDC national health report: Leading causes of morbidity and mortality and associated behavioral risk and protective factors - United States, 2005-2013.

41. https://www.cdc.gov/mmwr/preview/mmwrhtml/su6304a2 . htm

42. Everett, B., \& Zajacova A. (2015). Gender differences in hypertension and hypertension awareness among young adults. Biodemography and Social Biology, 61(1), 1-17. http://doi.org/10.1080/19485565.2014.929488.

43. Egan B.M., Zhao, Y, \& Axon, R.N. (2010). U.S. trends in prevalence, awareness, treatment, and control of hypertension, 1988-2008. Journal of the American Medical Association, $303 \quad$ (20), 20432050.https://doi.org/10.1001/jama.2010.650 